\title{
"I'll Look Into it!” Lubricants in Conversational Coproduction
}

\author{
Katarina Winter ${ }^{1}$ (iD
}

Published online: 20 January 2020

(C) The Author(s) 2020

\begin{abstract}
This study investigates the interaction between civil servants and politicians in a planning committee in a Swedish county council. As the committees are venues for preparation of future decision-making, civil servants and others are invited to inform and report to the politicians on different topics. The aim is to explore this local interaction process based on an analysis of requests and responses. It is shown that the communication between civil servants and politicians is pervaded by sociability in the form of conversational routines. The article aims to recognize this sociability as an intrinsic part of knowledge coproduction processes. Civil servants and politicians negotiate different types of professional and common knowledge through routines that dislocate time, responsibility, roles, and protocol order. These lubricants - important but often circumvented in studies of policymaking - are explored as instances of conversational coproduction.
\end{abstract}

Keywords Conversational coproduction - Expert communication - Civil servants · Politicians · Coproduction of knowledge $\cdot$ Conversational analysis · Conversational infrastructure

\section{Introduction}

Relationships between politicians and civil servants are characterized by an inherent conflict regarding expertise. On the one hand, expert and evidence-based forms of knowledge are highlighted as key to more effective decision- and policy-making in contemporary society (Schudson 2006). On the other hand, studies show that expert

Katarina Winter

katarina.winter@sociology.su.se

https://www.su.se/profiles/kawi3039

1 Department of Sociology, Stockholm University, 10691 Stockholm, Sweden 
knowledge is often applied in a highly strategic manner to legitimize decisionmaking (Boehmer-Christiansen 1995; Boswell 2009; Nilsson and Sunesson 1988; Stevens 2011; Tieberghien and Decorte 2013) and that certain expert knowledge is prioritized over other forms (Stevens 2010). Moreover, prior beliefs and ideology affect both politicians' processing of new information and knowledge (Baekgaard et al. 2019) and their decision-making (Eriksson and Edman 2017). This is unsurprising, given that politicians are surrounded by and positioned in several conflicting (individual/political/expert) knowledge processes, practices, and ideologies. Yet increasing calls for evidence-based policy-making (EBPM) require more focus on and action on the part of experts, and even critics set their hopes to increased forms of expertise (Leicester 1999).

One way to bridge these contradictory claims is to view and study the boundaries between science and policy, in general, as well as political knowledge processes, in particular, as continuously made and remade negotiation processes concerning conflicting ideologies, values and interests. In fact, this can be seen as the very foundation of the production of (political) knowledge (cf. Jasanoff 2004). Such an approach views knowledge as a process of co-constitution and negotiation. It also permits a focus on multiple and alternative dimensions in the production of knowledge, such as mundane conversation (Lynch 2004), and tensions within and between (actors in) conversations. Tension is, for instance, found in the relation between civil servants and their expertise, on the one hand, and the politicians and their knowledge, on the other, or in the relation between opposition and majority politicians.

The current article views and explores politicians' and civil servants' interaction in county council committee meetings as such negotiating processes. Previous research has problematized the boundaries and relations between expertise and society. The current article aims to shift the focus from the potential ideological, evidence-based, or value-laden knowledge to the verbal environment in which this knowledge is exchanged or, more precisely, to the conversational infrastructure in which knowledge is embedded. Naturally, the knowledge communicated between civil servants and politicians is important, but the channels of communication - the infrastructure of conversational routines through which the knowledge "flows" - are too. Conversational routines are crucial to understanding production, transfer, and exchange of knowledge, because they bridge and facilitate but also disturb these practices. Shifting the focus from what kind of expertise that is potentially exchanged to the surroundings of this activity will allow us to grasp how deeply tacit and unconscious ways of conversing govern our communication, and allow us to acknowledge a broader picture when thinking and theorizing about production and coproduction of knowledge.

Studies on knowledge coproduction usually draw on classical Science and Technology Studies (STS). Combining this strand with conversation analysis, I suggest that the concept of conversational coproduction ${ }^{1}$ is useful if we wish to explore how

\footnotetext{
1 I thank Mark Elam for suggesting the notion of "conversational coproduction." Although conversation analysts could talk about a conversational co-construction, or sometimes even a coproduction of knowledge, that regards the actual micro-situation, e.g., coproduction of learning in conversation (Boyd 2004), of meaning of an acronym in a group discussion (Bierbach and Birken-Silverman 2007), or of empathy between patient and therapist (Buchholz and Alder 2015), or the like. Here, the ambition is rather to
} 
knowledge activities are embedded in regulating conversational routines. Although I am not conducting a traditional conversation analysis in its stricter sense, the analytical concepts accounts (Scott and Lyman 1968) and paired activities (Sacks 1995; Silverman 1998) have inspired a detailed analysis of civil servants' and politicians' conversational routines within a local setting and of how they can be related to coproduction of knowledge at large as examples of conversational coproduction.

The aim is to characterize the debates within committee meetings by exploring the interaction of politicians and experts, focusing on their respective conversational routines rather than on the recommended decisions emerging from the meetings. The following questions guide the analysis. What conversational routines are used? What consequences do they have for the local interaction process? How are the informing-receiving roles and relationships of civil servants and politicians produced in this process?

\section{Knowledge is Strategy is Legitimacy is Value is Coproduced}

Knowledge transfer theorists (e.g., Weiss 1979, 1980) were early to problematize the instrumental view on relationships between expert knowledge and policy-making. Weiss (1980) argued that political decision-making is not a concrete and systematic process of instrumentally applied knowledge but rather an indistinct process into which knowledge "creeps." Following Weiss, Nilsson and Sunesson (1988) showed how expert knowledge is used for legitimizing purposes, and that the very same expert knowledge is applied and used in different ways. Several scholars within Science Policy Nexus (SPN) studies have continuously explored Weiss' conceptualizations (see, e.g., Ritter and Lancaster 2013) and how use of evidence serves a strategic purpose in the work of policy-makers (Boehmer-Cristiansen 1995; Boswell 2009; Stevens 2011; Tieberghien and Decorte 2013). Furthermore, Boswell (2009) highlighted that the use of expert knowledge is not as much about its content and quality, as about its credibility; use of expert knowledge creates authority to legitimize actors and activities, or substantiates their preferences and policy positions.

Other studies have also focused on the influence of values and ideology within policy-making and the political-expertise relationship (Tieberghien and Decorte 2013; Stevens 2007; Ritter 2009; Eriksson and Edman 2017; Fraser 2016; Lancaster 2014, 2016). In addition, Baekgaard et al. (2019) focused on the concrete interpretation process of politicians by showing that politicians reject evidence that does not conform to their prior beliefs. Although Baekgaard et al. (2019) argued that politicians ought to have more experience than laypersons regarding the handling of big and complex information, the politicians did not differ from ordinary citizens in their interpretations of new information and evidence.

Footnote 1 (continued)

understand how local conversational routines enable and coproduce interaction between science and society. 
Previous studies have offered a pluralist understanding of experts and expertise when acknowledging the involvement of a wide range of actors and knowledge from different domains. These studies have deepened our understanding of how knowledge within politics and policy-making is a multifaceted process involving more than objective and rational, evidence-based activities. ${ }^{2}$ However, several studies have treated expert knowledge as something that is constructed outside the political process (Weiss 1979), and/or reproduced a division between knowledge producers and their recipients, and between previous and new knowledge (Baekgaard et al. 2019). Such dichotomies can be useful in problematizing knowledge production, but they also risk reproducing settings, actors, and knowledge as either-or. In other words, when expertise is exposed as being pervaded by values and ideology, it is established as biased and/or untrue. But knowledge is not a clear-cut process, and being associated with beliefs and ideological values does not necessarily mean that knowledge is "false."

In contrast, scholars of STS and SPN have argued that we need to acknowledge the co-constitutive relationships in knowledge production and thus, for example, accept that and study how evidence is interpreted differently in different ideological positions (Jasanoff 2004; Lancaster 2016), and how expertise is constituted in interaction (Lynch 2004). Studies that see knowledge as negotiated and coproduced have offered crucial perspectives that help us understand how knowledge is unfixed and stabilized inside rather than outside these processes. The coproduction idiom allows different types of actors into knowledge processes but nonetheless applies an instrumental approach to what knowledge is influenced by (values, ideology, power, etc.). Regardless of the exact implications of coproduction, influences on values, ideology and other aspects, and simultaneous trust in experts, the problematizations of expert knowledge call for new types of understanding of knowledge making. We need to study how expert knowledge and its addressees co-create and are co-created in a process involving more than aspects solely associated with an independent expertise. The conversational routines of expert communication constitute one such aspect.

\footnotetext{
${ }^{2}$ In the current study, the term experts refers to the civil servants and other informing actors (heads or employees from the county administration, or from other organizations within the county council) invited to the county council planning committees because of their expertise on certain topics. Scholars have tried to elaborate on knowledge dichotomies by introducing additional forms of knowledge, such as civil servants' bureaucratic knowledge (McClean and Shaw 2005). Obviously, there are differences between, for instance, actors of scientific expertise and actors of administrative processes within politics, although the latter are also to some extent bearers of the formers' expertise. In the current article, I have not differentiated between the statuses of the informing actors. Although their affiliation may differ, their roles in the meetings are similar. They are contrasted against the politicians as they are all invited to the committee meeting to inform the politicians about activities related to upcoming or potential decision-making. It is the knowledge transfer process in general within these meetings that I am interested in, and therefore divisions are made in other instances, between informing actors and politicians, between majority and opposition politicians, and between protocol order and local meeting order. Thus, although the civil servants might not always be the producers, they are bearers and informers of expert knowledge, while the politicians are decision-making recipients and users of such informing activities. The politicians represent a group further down the hierarchy in the county council, hence they are not full-time politicians and often have other jobs. This makes the initial relation between experts and politicians quite solid. Analytically, however, this could potentially change.
} 


\section{Conversational Coproduction}

In the present article, I linger on an often overlooked, but immanent player in coproduction: the conversations that embed knowledge in processes of communication. Language clearly plays an important role in coproducing realities, and some previous work has also recognized this. The classical work of Peters (2001), Barry (1999), Collins (1988), and Shapin (1984) emphasized the linguistic dimension of knowledge production in terms of communication of how to conduct experiments, or how to write up experimental results. Moreover, Lynch (2004) explored how the acceptance of experts builds on interaction in the form of mundane conversations. The importance of conversations has been acknowledged, but previous studies have seldom offered a detailed analysis of or strategies for how to perform one. In addition, conversation in terms of sociability is seldom acknowledged, and when it is, it is framed as a supplementary part of (see, e.g., Lynch 2004, on use of mundane conversation to begin a discussion) rather than an inherent process of coproduction.

Sociability (Simmel 1949), in terms of everyday mundane conversations, can appear quite peripheral to knowledge contexts within politics. In the current article, I instead argue that sociability constitutes a central dimension in processes of coproduction and expertise. Myers (2004: 228) argued that "there is pleasure in the interaction for its own sake" and that sociability is not just a by-product but rather an essential part of "real social organization." In dialogue with Sacks, Goffman, and others, Myers (2004: 13) argued that while people say the most unpredictable and contradictory things, how they say these things is "surprisingly predictable." In other words, people rely on conversational routines to put forward their messages, as sociability brings actors together and enables tasks, strategies, or intentions.

What could be read from the above discussion is the importance of the meeting of conversational actors. The meeting as an arena for studying conversation is crucial, as meetings - that is, specific situations of co-presence of different (at the least two) actors - constitute and bring about expectations concerning how we to speak to each other. Schwartzman (1987: 274) defined meetings as "a social form that organizes interaction in distinctive ways":

...meetings do not simply "reflect" or "reveal" the social order outside a meeting but in many important ways the social order is made (produced, created, constituted) in the act of the meeting and this, in turn, creates the possibility for challenging, inverting, and subverting it. (Schwartzman 2017: 159)

Meetings are also constitutive of actors. Sandler and Thedvall (2017) argued that certain dimensions (practices, documents, discussions) set up frames for what can take place within a meeting. Meetings, however, are not only containers of these frames, but also interaction consisting of intentional and unintentional action (Schwartzman 2017: 12). In other words, meetings "make things happen" (2017: 15), as they are both "makers and breakers of social order" (Schwartzman 2017: 163). The social contexts for the current article, the planning committee meetings, are thus bearers of both the county council agendas and ambitions related to organizational order, ideology, economy, and relationships outside the local context; at the same time, the meeting itself enables potential alternative action. 
Following Lynch, Schwartzman, and Sandler and Thedvall, the present study contributes to the existing literature by addressing conversational routines in local interaction in terms of political meetings. Although actors can bring agendas, identities, and ways of speaking into a meeting, something specific happens when actors are separated from their initial activities and put in social, face-to-face situations that create their own local frames and routines. Actors need to conform to these routines because they tie actors to each other. Consequently, the local routines separate actors from their initial activities and contexts and, at the same time, are the communication channels - the enablers - of the very same activities, for example, knowledge transfer. The communicating actors will need to acknowledge and master the routines and the mundane talk in a situation to make themselves heard and perform their communicative task.

What do such activities do to processes of expert communication, and how are they part of coproduction? To view and explore the interaction between civil servants and politicians as conversational routines, I turn to classical sociological conversation analysis and Harvey Sacks' (1995) and David Silverman's (1998) works on paired activities as well as Scott and Lyman's (1968) accounts. Conversational routines as paired activities constitute the relationship between what has just been done and what comes into a process of interaction. A question presupposes an answer, a joke some laughter, an attack a defense, and so on. More specifically, the paired activities are analyzed as phases of accounts, as fundamental, ritualized processes of giving and taking (Scott and Lyman 1968). Actors use accounts to explain inconvenient behavior and prevent conflicts through bridging actions and expectations. Accounts are setting-specific and routinized within specific cultures, which means that they can be exclusive to sub-cultures or small groups as well, for example, within groups of friends, family, or at work. Whether accounts are reasonable or illegitimate depends on the background expectancies and status of the actors involved in the interaction. If the second activity - here, the civil servant's response to the politician's request - does not appear as expected, there is a need for a stand in, or an explanation (Silverman 1998: 107). Different types of conversational routines are used in the same sequences of requesting and responding, some of which are more "successful" in meeting the requests.

\section{Case and Method}

The previous sections outlined how expertise is an object of negotiation in the political domain, and it was argued that conversational routines are an important but overlooked dimension of coproduction. The case - a planning committee within a county council - was selected owing to its potential to offer insights into conversational coproduction and the relationship between knowledge providers and receivers. All politicians and civil servants are positioned within different praxes, ideologies, and decision-making. I chose the members of the planning committee because they offered engagement with a group of actors representing all county council parties rather than specific opposition or majority groups. The group members had several abilities, as they simultaneously represented the public, the receivers of information, 
and the actors making political decisions when they engaged with knowledge from civil servants. Moreover, I wanted to capture the interaction preceding the decisions to come. This made the political committee meetings suitable for analysis owing to the extended time for discussion. The case lives up to a traditional knowledge ideal, as this specific committee has extended their meeting hours, a change intended to increase the information and knowledge given to participants during the meetings. This decision-preparing stage contains more discussion and interaction than the future decision-making at higher levels in the county council organization, the Health Care Services Committee (Hälso- och sjukvårdsnämnden), which in turn stands under the County Council Executive Board (Landstingsstyrelsen) and the County Council Assembly (Landstingsfullmäktige).

The planning committee involves politicians, civil servants, and other experts within the extended organization of the county council, of which the two latter are called on to inform the politicians about various subjects. The group functions as a body that prepares decisions related to public health and psychiatry. Their meetings contain both preparation of decisions and information errands, aiming at informing politicians about work areas, reports or documents (statements of intent, policy guidelines, etc.) potentially related to forthcoming decisions. The decisions are informed by proposals from the Healthcare Services Administration (Hälso- och sjukvårdsförvaltningen).

The collected material consists of observations, audio recordings, protocols, and other documents from four group meetings (12 hours). I have prioritized discussions specifically related to matters of addiction, even if the committee discussed other areas of public health and psychiatry as well. The focus on four meetings permits a thorough analysis of patterns as well as nuances and alternative findings based on a manageable amount of data. Through detailed analysis of what a local political process looks like, the informing-receiving relationship is explored. The coding process focused mainly on the interaction following politicians' questioning and interruption of informing actors, in other words, on how the paired activities (cf. Sacks 1995; Silverman 1998) of requests and responses took place.

The software program Nvivo was used to perform the coding. I used an open and broad coding strategy inspired by Strauss and Corbin (1990) that basically involved asking questions (What is this? Who does it? How is it done? What does it represent? Why is it happening?), comparing within and between groupings of data. To keep track of the patterns of requests and responses, different layers of codes overlapped. Individual information like roles (opposition politician, majority politician, civil servant) or characteristics (talkative, silent, seldom occurrence at meetings, etc.) coexisted with codes for changes in, and challenges of such information. Besides coding and structuring every request and response, these were also coded as sequences to facilitate an understanding of the extended interaction surrounding a specific pair of phrases. A sequential view enabled me to see when actors returned to previously talked about subjects, or what consequences were brought in after requests and responses, for example, if the questioning or the meeting continued. I was interested in the more or less intentional routines that surrounded the topics discussed, and that both politicians and civil servants used. I looked for how requests and responses were introduced, received, acknowledged or rejected - how 
they shifted, stabilized, or repeated focus. The material was constituted by small and large consensus and conflict relations. When conflicting requests were raised, other actors met up with balancing strategies which had different outcomes in terms of increase or decrease of friction. After this structuring and sorting coding process I recognized a recurring pattern: Activities that referred to issues outside the present situation, for example, other settlements of time, roles, responsibility, and so on. The common traits of this recalling of different outside contexts were that they had dislocating consequences. Swedberg (2017), Mills (2000 [1959]), and Lave and March (1975) have highlighted the importance of considering the opposite of a concept when mapping out its meaning. Consequently, I posed questions like: What is not a dislocation? Something that sticks to the agenda. What is kept to the agenda? The factual information from the civil servants. This facilitated a view of how dislocations to some extent dominated the actual expert communication. Below I will present the analysis based on three themes of dislocation.

\section{Dislocation of Time, Roles, and Protocol Order}

This section introduces three types of conversational routines that embed, enable, and hinder knowledge exchange between civil servants and politicians. Dislocation of time refers to routines that in different ways ascribe action to the future, or bring future action to the present, for example, the phrases "I'll look into it" or "this is only a work in progress." Dislocation of roles is the routines that appropriated professional or other types of knowledge objects, often the individual or collective experiences of staff or patients. Finally, dislocation of protocol order means the routines that disturbed organizational routines, like the order indicated in the agenda or the protocol. The approach of conversational coproduction focuses on how tensions within these routines maneuver potential conflicts and flow or freeze the conversations.

\section{Dislocation of Time}

This section engages with conversational routines that brought the present into the future or the past, or the other way around. In other words, different ways of dislocating time. The focus is on the responses from civil servants to the requests from either individual politicians or (temporary) alliances. Actors maneuvered the requests and responses through different routines that were more or less successful in reaching (illusory) consensus and ending the questioning. In the example below, a politician asked a civil servant about indicators for addiction treatment during a presentation of the current and forthcoming pharmaceutical strategy:

Majority politician 1 (MP1): Are there any indicators for the addiction treatment?

Civil servant 1 (CS1): Well, we would rather not push forward a specific treatment area, but rather talk about the generic ones. Yes. But it's clearly the case that... 
MP1: I'm just thinking, because heart disease treatment was included...

CS1: You mean as indicators? We haven't had any indicators for addiction care. We don't. We have tried to pick these national indicators. Often, to be stable. But, and there are no [indicators for addiction care]. But I'll take that with me. (Meeting 3, Errand 6, sequence 46-49 [M3E6.46-49])

The civil servant met the politician's request by arguing that they prefer generic rather than specific areas of treatment, implying that this was the usual approach. The politician followed up with a question involving an argument based on the civil servant's knowledge source, the strategy document. MP1 argued that heart disease treatment was - just like addiction treatment - a specific and non-generic area, yet included in the strategy. CS1 repeated the initial argument that generic ("national") indicators are stable, adding that specific indicators do not even exist. But he also coupled it with another phrase: "I'll take that with me." Phrases such as "I'll look into it" (or similar examples like "I will check up on that" or "I will have to get back to you on this") were frequently used by civil servants (around 10-25 times per meeting). Here, the civil servant's "I'll take that with me" indicated that he would bring the question of specific addiction treatment indicators into a future work process. On the one hand, this suggested that the politician's request was right and could impact future work on the strategy. This left limited room for the politician to continue the questioning, as her wish to highlight addiction treatment was confirmed. On the other hand, this opposed the civil servant's professional argumentation on the impossibility of such indicators: "we'd rather not," "we'd rather instead," "we don't have any," "we use stable ones," "there are no." Instead, the civil servant was left to a tension in the future work process between his confirmation that this was something noteworthy to bring back to work, and his initial claims of "we" - the administration - neither preferring, wanting, nor being able to.

Whether this knowledge exchange had an actual impact on the continued work performed by CS1 is unclear, but even if the work process or the actual indicators in the pharmaceutical strategy did change, this would still conflict with CS1's initial approach. Although this favored the politicians' request, the relation between the civil servant's and the politician's knowledge was stressed, as they both used the pharmaceutical strategy as the source of their opposing claims. By displacing the time frame to an abstract future, the tension caused by the request was relieved within the direct situation in the meeting. The dislocation functioned as a way for civil servants to maintain expertise and end the questioning at an 'illusory consensus,' allowing the meeting to continue.

Other situations confirm this exchange, but not always with the same outcome. During a presentation of a new collaboration policy between the county councils and the municipalities, a politician asked whether needle exchange programs (NEPs) were discussed in the policy (M1E3.56.MP1). The invited actor (CS2, an expert from the policy working group and head of an addiction treatment clinic) first argued that including NEPs in the policy lacked relevance, but after persistent questioning from the politician, he added "I'll take it with me," which successfully met the request, implied a future change, and ended the questioning at a consensus (M1E3.56-74). Despite the initial differences in civil servants' and politicians' views 
of the (ir)relevance of the request, the NEPs were added to both the protocol and the policy document. In this example, the expert knowledge was challenged both in the real time setting and in the future, as the document was adjusted to the benefit of the politician.

The two examples illustrate how conversational routines were structured during the meetings. As politicians interrupted the informing actors with questions, the informing actors initially reacted based on a professional discourse ("it cannot be done because," "it is not relevant," etc.) These responses were of course also conversational routines, based on the specialized knowledge of civil servants. But they were not enough. Instead, by changing their responses to "I'll look into it," civil servants adjusted to the expectations, dislocated the time for action and avoided a more dramatic debate on who was right.

Moreover, the politicians used "I'll look into it" when the majority politicians were questioned by the oppositional politicians, or when politicians demanded civil servants to look into an issue. The phrase could then end the questioning in a similar way as shown above, but it could also result in wanted or unwanted extra work when a rephrasing took place in which critique was directed to civil servants or other informing actors in terms of "you should look into it." This latter maneuver, so to speak, dislocated the dislocation of, for example, time into other dislocations of responsibility. Another time account was to refer to the object in question (a report, a valuation, a strategy plan, a policy) as work in progress. Such responses involved arguments that it was "too early to answer these questions" or "we have more recent figures to consider," and so on. This often had the same connotation as "I'll look into it." In other words, a future work process, into which no one but the civil servant had insight, was the time for resolution:

MP1: Next time, it would be great if we could get a clear overview rather than this running text of different comparisons.

CS3: I understand.

MP1: This is a bit too difficult.

CS3: But the report is not finished yet, this is more like a... I just didn't want to show too many figures because I'm not yet sure if they will change. But there are a lot of figures in this report.

$[\ldots]$

OP1: So, when will we have access to the finished report?

CS3: Well, it was supposed to be finished this week...

OP1: Okay.

CS3: But we had a few points on the writing, so they will have to correct a few things, and I hope that you'll have it next week or so.

Several politicians emphasized the difficulties in understanding the report. The response from CS3 was that "the report is not finished" and that the figures were not final. What was discussed as unclear was the qualitative content of the text rather than the statistics. Although the report was to be finished "this week," the civil servant nevertheless responded that she would fix the clarity problems of the report when OP1 demanded that she "look into it." Moreover, in other examples, civil servants could reject similar requests as too early to answer and suggest, for example, 
a future response to the requests. The next time, this could either happen all over again - "this is just work in progress" - or potential comments were too late, as it was presented in its final, published form.

A similar routine was the phrase "it's very complex." One could interpret such outbursts as expressions of humility considering the complexity of the topics discussed, for example, addiction, eating disorders, treatment, and so on. Such an approach works in line with recent research arguing that policy-related decisionmaking must be more reflexive and perspective-pluralistic to avoid unidimensional, simple, and short-sighted problem-solving. On the other hand, these statements were often followed up by simple and concrete solutions to the problems discussed. For example, when diseases were discussed in the meetings, they were often surrounded by statements concerning their respective complexities. Few detailed professional claims were communicated. Instead, civil servants maintained their expertise by distancing themselves from simplicity and voicing (cf. Myers 2004) other persons' stereotypical and naïve approaches, such as "Not all addicts are found on park benches" (M1E3) and "It's not that easy to just start eating" (M3E8) about eating disorders). When I asked the civil servants about the issues debated in the meetings, they explained things to me in quite simple ways in terms of altruistic arguments. When complexity was stressed in conversations with me, it concerned other things, mainly the difficulties in collaboration between the municipality and the county council. In this way, we can understand that "It's very complex" works more as a routine used by civil servants toward politicians than toward a researcher, although both are asking questions about the same topics.

Informing actors were invited to the meetings to deliver reports on different work areas within the county council. It was expected that argumentation based on their expertise, as well as intake and discussions of this knowledge, would characterize the interactions between them and the politicians. The politicians' requests were seldom met by professional argumentation only. However, as shown in this section, the civil servants initially often responded to politicians' requests by referring to their professional knowledge and work procedures. When they were met by additional requests, there were also other ways to negotiate by pairing the requests with other types of routines. Civil servants tried other arguments, for example, "I'll look into it," "This is work in progress," or "it's very complex," which could end the questioning and potentially protect the initial professional argumentation. These time dislocations also had something else in common: they all reflected a certain degree of uncertainty. It was not certain whether or when something was going to happen, or what it would look like. Uncertainty was also found in the talk of civil servants in general, through their use of a disarming and rallying tone in relation to themselves. This conflicts with previous studies. For example, Stevens (2011) argued that, for the civil servants in his study, uncertainty was the worst thing to send out, and Boswell (2009) showed how uncertainty was reduced through strategic use of evidence. In the current study, actors allowed for uncertainty when politicians did not push the civil servants to provide exact figures, arguments, or facts, but instead allowed them to rely on a position that accepted "not yet knowing." The politicians, on the other hand, did not show uncertainty at all during the meetings, although the meeting hours had been extended to include more information and learning 
for the politicians. The prolongation of meeting hours could have implied that the politicians were open to learning about new and to acquiring more knowledge. But instead, the extra hour was filled with requests that caused the civil servants to distance themselves from their professional argumentation and conform to certain routines that stabilized potential conflicts into sociable and polite conversations.

In this section, I have mainly discussed the responses and how they negotiated knowledge in terms of ending discussions at (illusory) consensus through routines that displaced time and concreteness. But the requests also involved routines. In the hitherto mentioned examples, this often took place through either alternative use of civil servants' knowledge sources, or by bringing in the experiences of other actors (staff or patient groups). This is further investigated in the next section.

\section{Dislocation of Roles and Responsibility: Voicing and Seriousness}

In the first quote in the previous section, CS1 tried to support his own claims by repeating his professional knowledge, before he conformed to routines of time dislocation. Likewise, MP1 drew on the civil servant's knowledge source - the strategy plan - to argue for the importance of indicators for addiction treatment: "I'm just thinking, because heart disease treatment was included." Use of civil servants' knowledge objects (strategy plans, collaboration documents, reports, etc.) was a reappearing activity in the meetings and challenged the relationship between informing and receiving actors, as well as the position of the civil servant. Yet there were also other ways to start up a discussion or to interrupt an informing actor, either through an individual experience of something ("this is how I experienced this matter"), stories about family members' experiences ("my family member has this disease"), or referring to others' collective experiences ("staff groups are telling me," "patients are telling me"). For example, using one's own, friends, families', and whole populations' lived experiences, one politician (MP3) argued that the interventions presented by the civil servant (e.g., plain or picture packages and tax increases) only caused "short-lived chock effects" on smoking cessation. This challenging request was met by a comeback from the informing actor: "We only have access to national level data" (M2E1.15-20). The response almost literally reflected CS1's professional claims-making in the previous section on national indicators, as well as its insufficient outcome, as the politician did not stop the questioning. CS4 in the smoking cessation example assured the others she would look into it, and MP3 persisted in drawing on collective experiences of smoking cessations followed by suggestions that they should "dig into this some more," in other words "You should look into it." Routines involving professional or common (individual or collective experiences) knowledge could be read as means for increasing the tension between civil servants and politicians, for example, in terms of questioning the efficiency of the interventions presented. While the politicians could alternate between these types of claims, the civil servants were most often restricted to the professional argumentation domain.

Routines involving collective experiences could also cause tension between other actors, for example, between the opposition and the expert, on the one hand, and the 
majority, on the other. For example, this happened when politicians drew on collective experiences when taking on the task of speaking for the weak or the mistreated. Such "people are telling me" stories about concrete or abstract groups of publics, patients, or staff worked as negotiators between civil servants and politicians. The following example is from a discussion on qualitative reviews in healthcare ${ }^{3}$ :

CS3: A care plan is an incredibly high predicator of this working. But, care plans are largely missing.

OP1: This is deadly serious, and a problem that we hear from patients too, there is no care plan, but why is there no care plan?

CS3: Yes, that's a very good question.

OP1: Is it because of time limits, because of ignorance, because of staff turnovers, I mean... Why does it look this way? It must be obvious that a patient in psychiatry needs a proper care plan?

CS3: Well, I don't really have a simple answer to this. I think it depends on possibly all these things you said. And also, that they, do not really want to accept this, how important this is. They seem to think that, I know best what you need.

[...]

OP2: What do the care givers answer when you ask them directly about this? Why don't you use care plans?

CS3: Yes. One could say that some respond like, 'wow, this is great to know, we don't have a grip on this,' and then they make a plan and say thank you and good bye. While others are more insulted, claiming that we are wrong, our evaluation is wrong, we don't understand anything [laughter]. 'You're just idiots.' Defensive. (M3E7.1-9)

CS3 opened up for interruptions when stating that care plans are necessary for treatment to work, and immediately continued by explaining that care plans often do not exist. Consequently, three opposition politicians in a row interrupted the presentation with arguments and requests concerning what "patients tell us" (OP1), "my work experience is" (OP1), "patients need" (OP2), that "patients' safety is in danger" (OP3). CS3, in turn, navigated between dislocations of responsibility - care givers don't understand; think they know best; are offended; call us idiots - but also confirmed and repeated the politicians' requests, which strengthened the notion that the politicians' claims were realistic and relevant.

As Myers (2004: 168ff) showed, actors can provide different representations of themselves and others by voicing other positions. In the above example, this concerns collective voices, while other examples concern individual but multipleexchangeable voices. For example, one politician drew on their mission as jurymen to claim that use of cannabis and other drugs has increased in general and in youth groups in particular. Although the group is (naturally) polarized between the opposition and the majority, the use of either one's own or others' - not present in the group meeting - voices could imply that the planning committee is a united force,

3 The discussion is edited a bit to show the main line of interactions. 
able to solve the problems raised by the informing actors. When these agreements are vague but personified, they can reconcile and conceal otherwise fundamental conflicts. For example, general statements on the collective voice of stressful personnel illustrate how personified claims could "trailblaze" potential consensus and avoid debate. When it comes to more concrete but structural statements, however, like about low salaries or unequal healthcare causing problems, this changes. The four actors (CS3 and three opposition politicians: OP1, OP2, and OP3) in the example above seemed to agree on the importance and definite character of the care plans as they took turns guessing why this is the case. We can catch a glimpse of a rising consensus activity between the requesting and responding actors: "Yes, that's a very good question"; "I think it depends on possibly all these things you said." Such phrases confirmed the politicians' requests, but there was no tension because the action - how to actually deal with this problem - was peripheral since the responsible actors were not the civil servants but the care providers. In other words, CS3 could answer why requests by taking sides with the politicians and bringing in the care providers, characterizing them as responsible by voicing them as rude and defensive. But just as in previous examples, consensus between some actors brings about tensions between others. While consensus between the opposition politician and the informing actor was kept, consensus between opposition and majority politicians decreased. Making requests to informing actors is therefore a way to question existing politics and thereby also majority politicians. The next phase of the discussion explored above illustrates how new conversational partners, the majority politicians, join the discussion and provide an alternative response to the request raised by the opposition politicians:

MP1: It's great that this gets you started [scattered laughter around the table], and this was one of the reasons for us when we initiated these reviews.

$[\ldots]$

MP2: Can I please make a request? [Slightly laughter] It's very easy to get stuck on specific areas. The most relevant and important question is actually what the process and the future will look like.

CS3: Absolutely. (M3E7.21-23)

Following the previously discussed consensus activity in which the civil servant confirmed the three opposition politicians, MP1 jokingly commented on OP3's commitment, and MP2 continued this attitude when minimizing the care plan discussion to "specific areas" in contrast to the "relevant and important" process. Care plans were now downplayed, from main indicators of increased quality to a peripheral interest. This dislocation of seriousness or focus took the discussion back to general sweeping information on the quality review report, and also brought in the majority as the actors in charge. Thereafter, however, MP2 returned to care plans:

MP2: This is very serious.

$[\ldots]$

CS3: Yes it is.

MP2: It is extremely...

CS3: It's very bad. 
MP2: No [laughter], it's not very bad, it is extremely, irredeemably remarkable.

[multiple voices]

CS3: Yes, it... [laughter]

MP2: And this kind of requires that, [laughter], well one cannot really physically grab somebody and tell them off, but as closely as possible, frankly.

CS3: Yes.

MP2: So therefore I want to see how this comes into process, this is not okay, I want to know, what, how does one make sure that this is changed, and how is it followed up on, and how does one create a dialogue with the patients to make sure they get what they need. This is what I hope we will get.

(M3E7.60-68)

Instead of downplaying, the majority politician now took the care plans "very seriously" and described the lack of them as "extremely, irredeemably remarkable." The questions MP2 asked reflected those posed earlier by the three opposition politicians, only turned from why questions into how and what questions. Moreover, MP2 undermines CS3's professional argument on proposed interventions: "This requires much clearer and more powerful measures than just scarcely stating that you will write down what you do and six months later you will do a follow-up on it." This example shows both how MP2 took over the conversation and the responsibility for claiming the importance of the issue as well as for deciding what the right kind of interventions could be.

While certain politicians often used the collective voice of personnel or patients and gained the prerogative to talk about certain topics and what these topics could contain, civil servants could seldom give in to individual or collective experiences. When they did, this mainly regarded voicing others (the public or caregivers) as naïve or rude, which could strengthen their argument about complexity or responsibility, but not affect or define the topic under discussion. The politicians, on the other hand, managed to jump between civil servants' knowledge sources and voicing individual and collective experiences, often in terms of victim stories. Victim stories referred to groups or individuals suffering from diseases or decisions related to their condition, such as gambling problems not being treated in the same way as substance abuse problems. These three approaches were all effective means for challenging or confirming the informing actors, although victim stories were the most successful (cf. Winter 2019a). This challenged the division of roles as either an informing or a receiving actor. In a way, this means that the civil servants' maintaining of their role through professional claims-making was undermined by their inability to use other types of claims, or rather, by the politicians' ability to use different types of routines that either drew on the civil servants' knowledge objects or individual or collective narratives that were brought in from outside the meeting context.

\section{Dislocation of Protocol Order}

One consequence of certain discussions within the committee meetings was that the conversational routines dislodged other routines, such as the organizational 
procedures indicated by the meeting agenda or the protocol. The planning committee's agendas brought expectations, for example, that the group discussion would result in preparations of decisions rather than actual decisions. Still, there was confusion regarding these and other premises within the meeting, and it seemed as though the meeting fulfilled both the making and the breaking of order (Schwartzman 2017). Reappearing situations concerned, for example, discussions regarding the opposition and their proposals' (motioner) relation to those of the administration. This is shown in the following example:

OP1: I wish to call for this report (motion) to be approved [others: affirmatory mumbling].

MP1: Yes, but you cannot do that here [in the planning committee].

OP1: But we can't just sit here and make a decision that I'm not able to affect!

That is so strange, it will look like I have confirmed this decision! [others: affirmatory mumbling] I must get to say what I want?

[a long discussion with unclear outcomes continues]

OP1: I have a feeling that we have had this discussion before.

MP1: Yes, yes! Several times!

OP2: Here we go again...

MP1: Exactly. [others: mumbling, laughter]

OP4: But it is really unclear... [others: interrupting mumblings]

OP1: I just want my report approved! [laughter] (M1E1.31-43)

This example illustrates a reoccurring activity within the meetings, an uncertainty regarding the procedures involved in preparing decisions. This very meeting had started with a repetition of these procedures: "It is the proposal of the administration that we should take a stand on." Just seconds later, the opposition politician OP1 calls for an approval of their report, upon which the majority politicians again explain that this is not the way it works. It was neither the first nor the last time this was up for discussion. A similar example of how the work procedure was disturbed regards the reactions of one opposition politician to a presentation by a civil servant on a proposed support line:

OP3: So when is this ready, is there a plan for when to launch this project?

CS9: No, we do not have a plan for it since we first had the task of investigating this question and next we will leave the investigation to the Health Care Services Committee. And then...

OP3: So, the next step is that the Health Care Services Committee makes a decision about it and then launches the plan, right?

CS9: Well, they have to make a decision about giving the mission to the administration to start this up. (M4E4.8-11)

Here, OP3 handles the information on an investigation of a potential support line like a final decision. Disregarding whether this is because OP3 knows that the proposal is likely to result in a final decision, OP3's request reflects the initial example. A third and last example shows further ways in which uncertainty was produced. The collaboration policy discussed in the previous section was initially a surprise to most participants: 
OP1: Can I just ask you...

CS2: Yes.

OP1: [reading from PowerPoint] Care in collaboration, political management group, who are the political management group?

CS2: [silence] ehhh. Well, you got me there, heh.

OP1: Is it this committee?

MP1: No. It would be suitable if you looked into this.

CS2: Yes.

$[\ldots]$

OP1: Can you please check up on this.

MP1: Absolutely, this is actually the first time I've heard about this. But we will definitely get back to this next meeting.

OP1: Yes, because it is important.

MP1: Absolutely, it's really significant information. (M1E3.5-20)

This example starts with a question from OP1 on who the politicians in charge of this work are - is it possibly the committee? As the quotation shows, not only MP1 seems confused, but also the informing actor CS2. MP1 then jumps in with a demand to CS2 to look into this. Later, MP1 also gets this demand from OP1 "Can you please check up on this," a question that MP1 meets with "We will definitely get back to this next meeting."

The three examples above reveal the different views on the task of the committee. There already existed a protocol for how to proceed with these activities, but the meetings seemed to allow for - or possibly sanction - a parallel structure. This parallel structure involved friendly quarrel back and forth that to an outsider appeared quite strange, not because the conversations involved odd topics, but because the protocols and setting presented a very clear and repeated order of things, as well as a repeated language for how to communicate the order of things. Surely, the members of the committee and the associated civil servants must have known very well that it is not possible to confirm a report already at this stage of the county council hierarchy, that investigations are not final proposals on interventions to come, and on which grounds informing actors are invited. At the same time, the meeting enabled routines that disturbed the order of organizational routines. Moreover, these and other similar activities often took some time to sort out during the meeting. Taking the time for long discussions about "problems" that are already sorted out reflects a routine itself. As Boswell (2009) explained, internal legitimacy in terms of certain shared beliefs, routines, and norms reduces uncertainty within an organization. But, in the current study, these routines, at least on the surface, produced a great deal of uncertainty. This was the case in the dislocation of time discussed in the previous section as well as in the dislocation of order. It is, of course, possible that this level of the county council allows for uncertainty while other levels do not. Nevertheless, it articulates a kind of internal legitimacy that might be as important as the organizational frames for action within the county council. 


\section{Discussion and Conclusion}

The present study has explored the interaction between civil servants and politicians in a planning committee in a Swedish county council. Because studies increasingly focus on actual knowledge production within politics, we tend to forget other processes in the milieu in which it takes place. Political arenas are pervaded not only by beliefs, values, and ideology (cf. Boswell 2009; Tieberghien and Decorte 2013; Stevens 2007; Monaghan 2010; Ritter 2009; Eriksson and Edman 2017; Fraser 2016; Lancaster 2014, 2016), but also by other social dimensions, such as emotions (Roumeliotis 2016; Hermansson 2018). The current article adds to this tradition the importance of conversational routines. This infrastructure through which knowledge is transported is not innocent (cf. expert communication is not innocent, Davies and Horst 2016: 216, 228). Instead of showing how and which knowledge is influenced by what, the contribution in the present study is instead an analysis of the conversational infrastructure and how it matters for communication processes. The focus is on conversational routines in terms of request and response accounts that emerge during civil servants' informing errands, and what consequences these have.

The analysis shows processes of decreased or increased tension: to different extents and between different parts of a conversation. The tensions presented in the introduction - between civil servants-politicians and majority-opposition - run through the material and get company from an additional tension couple: protocol order-internal order. The tensions are stable enough to be recognized but are also provisional to some extent, as actors produce temporary alliances. The outcome of tensions should therefore not be read as permanent conflicts. Rather, the tension between civil servants' claims, politicians' questioning of the claims, and the civil servants' responses can intensify and transform into a conflict, or decline and transform into consensus. Routines within these tensions are productive because they establish relations between actors and connect us with our conversational partners.

The conversational infrastructure contains request and response accounts, in which civil servants and politicians negotiate different types of professional and common knowledge through dislocations. Responses in terms of professional argumentation based on the specialized knowledge of civil servants are of course also a routine. But such responses are seldom sufficient in ending politicians' requests on a specific topic but instead accompanied by dislocations. Dislocations are the functions of accounts and they all have in common that they appropriate something: time, roles, order. Certain reoccurring phrases ("I'll look into it," "this is work-in-progress"), voicing (staff narratives on resources, victim narratives from patients, etc.), and topics (disturbing the organizational procedures or changing the subject) are analyzed as more or less successful dislocations. The dislocations work as bridges, not only between actors but also to the next errand in the protocol, as they create illusory and provisional, rather than final consensus. How this takes place is regulated by the conversational infrastructure: allowing mundane quarrel and chatting creates flow in communication.

What is in focus in the present study is thus the lubricants of decision-making rather than the hands-on definite decision-making. The concept of lubricants 
helps us understand that it is not only the urge for consensus in a specific political field or topic that is in question here, but the urge for consensus as conversational partners. The consequences of lubricants are primarily not that they make expertise flow into persons' minds, but that expertise flows throughout (and out of) the meeting and its interacting actors with little friction. One can understand the conversations within policy contexts as influenced by a powerful sociability that makes keeping a conversational consensus and avoiding conflicts more important than the complexity and core of the communicated expertise. One can also understand these routines as strategically used by the different actors in conversation, that is, to view the dislocations as substitutes for inappropriate or impolite accounts. Achieving provisional consensus in these reoccurring conflict-ridden situations matters since actors that will meet each other again and again cannot - according to their conversational contract - continuously disqualify each other. Instead, they need ways of communicating that smooths things out. Consensus is in this way shown time and time again, but the study of sequences shows how this is rather a matter of repeated conflicts paired with dislocations. The examples are locally situated processes, but they contribute to the wider discussion on consensus through differentiating provisional consensus from consensus in general. Provisional consensus matters for expert communication since it reproduces expertise as something that flows through meetings, protocols, and conversations relatively undisturbed. There is no consensus in terms of collaboration or joint understanding of a political problem; provisional consensus helps out avoiding the collective, avoiding the group understanding and avoiding a joint path forward. This is at least the case for the civil servants as disqualifying and conflicting with the politicians would mean to disqualifying representatives of the public. As representatives of the publics however, the politicians on the other hand have other possibilities as their dislocations often bring in challenging voices. Routines thus act and coproduce, and enable flows of communication, but can also trouble expert communication. This does, however, not stop but is decidedly part of coproduction processes.

The explicit purpose of the information errands at the meetings is knowledge enhancement. This was argued by both civil servants and politicians in individual conversations with me. But the civil servants do not merely function as a source of information. They are often met by questions that ignore, challenge and oppose, rather than request clarification of, their professional argumentation. This is not to say that the extra hour spent on more information is not about policy-relevant knowledge, but that both politicians and civil servants are active in what this knowledge is about, for example, collective stories of staff or patient groups rather than initial information topics written in the agenda. The study shows that the agenda for the meeting (the topics on the written agenda and the explicit purposes of the meetings) interacts with the practice of the meeting. An important result of the study is therefore that the conversational routines engage with both the protocol order and the group order. Although there exist organizational frameworks in terms of procedures structuring the meetings, it is not possible to exclude the sociability that works with and against these objects. In this way, the study offers insights into the practice of protocol order. Conversational routines are not issues of locality but rather 
integral parts of the procedures and structures of politics because they take part in producing them. Civil servants abandon their professional argumentations and give in to these routines to avoid conflicts, stabilize their position, maintain expertise, and end questioning. But using them also confirms an everyday jargon and logic and the possibility to use this logic in expert communication processes. Something crucial is thus found in what often seems to be polite and/or neglectable small talk.

The study focuses on the conversational infrastructure that rules the expert communication at this level of organization. It is probable that the findings are mirrored in similar political contexts characterized by interaction and discussion between civil servants and politicians (in the municipality etc.). Additional studies could therefore increase the understanding of the everyday of policy contexts. One could expect other types of routines in settings higher up in political hierarchies, for example, in settings where there is no or little time for discussion of decisions, or where there exist strong permissions to conflict with each other (e.g., plenary debate). The development to involve the public not only as represented by politicians but also in terms of specific NGO's, advisory user groups, and so on certainly opens up for more studies of influences on expert communication processes.

The recent decades have witnessed a rising ideal on rationality and expertise as the solution to political problems (Mouffe 2005; Roumeliotis 2016). The present study opposes the scientific-rationalistic tendencies of contemporary politics. Not only does this view political problems as objects outside the collaborative construct of politics, it does also view expertise as outside conversation. As this study shows, there are several aspiring knowledge subjects within the meeting, in which the politicians often are conflict risers while the civil servants are provisional consensus providers. The actual political problems discussed are simultaneously treated as areas of professional and common knowledge. Topics are in this way depoliticized, but not in favor of rationality but in favor of everyday knowledge embodied in the politicians objections against the communicated expertise.

The conversational routines are investigated within the specific culture of politics. The activities that the civil servants and the politicians participate in and deal with, however, are not extraordinary or specific. They talk, argue, joke, and laugh together, and they perform routines of giving and taking to prevent conflicts (cf. Scott and Lyman 1968), and to initiate them. The theoretical perspectives of knowledge coproduction and conversational analysis facilitated an exploration of how a local setting of expert communication is influenced by mundane conversational routines with different dislocating functions and lubricant effects. While earlier research has focused on the construction of, potential ideological influence upon, and potential transformation in knowledge claims, for example, how knowledge claims lose certain meaning and gain new ones, this study instead points at another often neglected but central dimension of knowledge production in expert settings. In other words, the analysis in the current study shows how mundane infrastructure surrounding expert communication also matters for the very possibility to succeed in communicating. To some extent it even dominates the knowledge exchange. So how can we understand how local conversational routines enable and coproduce interaction between science and society? This study witnesses a need to ascribe importance to the jargons and conversational routines that produce and are produced within expert 
communication. There are of course different types of jargons, but as I have also stated elsewhere (Winter 2019a, b), everyday experiences and activities tend to infiltrate expert communication processes in delicate ways. We should therefore study conversational modes as actors and explore their agency, as they are premises rather than threats against communication. Consequently, when we, with the help of coproduction approaches, acknowledge that science and society are produced by and are producers of actors (Latour and Woolgar 1979; Knorr-Cetina 1981) and that they cannot be studied as separate but co-constitutive domains (Callon 1999; Jasanoff 2004; Shapin and Shaffer 1989) of nonlinear relations, we also need to acknowledge the interaction between different ways of conversing and how conversational infrastructures are productive in expert communication. The problematizations of experts, expertise, and expert communication in the recent decades of research within STS call for new types of studies of how expert communication takes place, what enables or hinders it, and how it is coproduced in processes involving more than isolated expert aspects. The conversational infrastructure that embeds communication is one such aspect. The current article demonstrates an example of what to look for and how to do it.

Acknowledgments Open access funding provided by Stockholm University. I am truly grateful for the civil servants and the politicians' participation in this research. I would like to thank Johan Edman and Mikaela Sundberg for commenting on earlier drafts, and Mark Elam, both for important comments and for suggesting the notion of conversational coproduction. For constructive comments in the final stage of writing this article, I want to thank Livia Johannesson, Lovisa Näslund, and Renita Thedvall at the Stockholm Centre for Organizational Research (SCORE). My deepest thanks also to the anonymous reviewers for their stimulating and constructive feedback. This work was written within the project Knowledge production, communication and utilization: Biomedical alcohol research as an emerging field of knowledge, funded by FORTE, the Swedish Research Council for Health, Working Life and Welfare (2012-0691).

Open Access This article is licensed under a Creative Commons Attribution 4.0 International License, which permits use, sharing, adaptation, distribution and reproduction in any medium or format, as long as you give appropriate credit to the original author(s) and the source, provide a link to the Creative Commons licence, and indicate if changes were made. The images or other third party material in this article are included in the article's Creative Commons licence, unless indicated otherwise in a credit line to the material. If material is not included in the article's Creative Commons licence and your intended use is not permitted by statutory regulation or exceeds the permitted use, you will need to obtain permission directly from the copyright holder. To view a copy of this licence, visit http://creativecommons.org/licen ses/by/4.0/.

\section{References}

Baekgaard, Martin, Julian Christensen, Casper M. Dahlmann, Asbjørn Mathiasen, and Niels B.G. Petersen. 2019. The role of evidence in politics: Motivated reasoning and persuasion among politicians. British Journal of Political Science 49(3): 1117-1140.

Barry, Andrew. 1999. Demonstrations: Sites and sights of direct action. Economy and Society 28(1): 75-94.

Bierbach, Christine, and Gabriele Birken-Silverman. 2007. Names and identities, or: How to be a hip young Italian migrant in Germany. In Style and social identities: Alternative approaches to linguistic heterogeneity, ed. Peter Auer, 121-154. Berlin: Mouton de Gruyter.

Boehmer-Christiansen, Sonja. 1995. Reflections on scientific advice and EC transboundary pollution policy. Science and Public Policy 22(3): 195-203. 
Boswell, Christina. 2009. The political uses of expert knowledge: Immigration policy and social research. Cambridge: Cambridge University Press.

Boyd, Gary M. 2004. Conversation theory. In Handbook of research on educational communications and technology: A project of the association for educational communications and technology, ed. David Jonassen, 179-197. Mahwah: Lawrence Erlbaum.

Buchholz, Michael B., and Marie-Luise Alder. 2015. Communicative violence in psychotherapy. Language and Psychoanalysis 4(2): 4-33.

Callon, Michel. 1999. The role of lay people in the production and dissemination of scientific knowledge. Science, Technology and Society 4(1): 81-94.

Collins, Harry M. 1988. Public Experiments and Displays of Virtuosity: The Core-Set Revisited. Social Studies of Science 18(4): 725-748.

Davies, Sarah R., and Maja Horst. 2016. Science Communication Culture, Identity and Citizenship. London: Palgrave Macmillan.

Eriksson, Lena, and Johan Edman. 2017. Knowledge, Values, and Needle Exchange Programs in Sweden. Contemporary Drug Problems 44(2): 105-124.

Fraser, Suzanne. 2016. Articulating addiction in alcohol and other drug policy: A multiverse of habits. International Journal of Drug Policy 31: 6-14.

Hermansson, Klara. 2018. The role of symbolic politics in exceptional crime policy debate: A study of the 2014 Swedish general election. Journal of Scandinavian Studies in Criminology and Crime Prevention 19(1): 22-40.

Jasanoff, Sheila. 2004. States of Knowledge: The Co-Production of Science and Social Order. London: Routledge.

Knorr-Cetina, Karin D. 1981. The manufacture of knowledge: An essay on the constructivist and contextual nature of science. Oxford: Pergamon Press.

Lancaster, Kari. 2014. Social construction and the evidence-based drug policy endeavour. The International Journal on Drug Policy 25(5): 948-951.

Lancaster, Kari. 2016. Performing the Evidence-Based Drug Policy Paradigm. Contemporary Drug Problems 43(2): 142-153.

Latour, Bruno, and Steve Woolgar. 1979. Laboratory life: The social construction of scientific facts. Beverly Hills: Sage.

Lave, Charles A., and James G. March. 1975. An introduction to models in the social sciences. New York, NY: Harper \& Row.

Leicester, Graham. 1999. Viewpoint: The Seven Enemies of Evidence-Based Policy. Public Money and Management 19(1): 5-7.

Lynch, Michael. 2004. Circumscribing Expertise: Membership Categories in Courtroom Testimony. In States of Knowledge: The Co-Production of Science and Social Order, ed. Sheila Jasanoff, 161-180. London: Routledge.

McClean, Stuart, and Alison Shaw. 2005. From Schism to Continuum? The Problematic Relationship Between Expert and Lay Knowledge-An Exploratory Conceptual Synthesis of Two Qualitative Studies. Qualitative Health Research 15(6): 729-749.

Mills, C. Wright. 2000. The sociological imagination. Oxford: Oxford University Press.

Monaghan, Mark. 2010. The Complexity of Evidence: Reflections on Research Utilisation in a Heavily Politicised Policy Area. Social Policy and Society 9(1): 1-12.

Mouffe, Chantal. 2005. On the political. Abingdon: Routledge.

Myers, Greg. 2004. Matters of opinion: Talking about public issues (Studies in Interactional Sociolinguistics). Cambridge: Cambridge University Press.

Nilsson, Kjell, and Sune Sunesson. 1988. Konflikt, kontroll, expertis: Att använda social forskning. Lund: Arkiv.

Peters, John D. 2001. Witnessing. Media, Culture and Society 23(6): 707-723.

Ritter, Alison. 2009. How do drug policy makers access research evidence? The International Journal on Drug Policy 20(1): 70-75.

Ritter, Alison, and Kari Lancaster. 2013. Measuring research influence on drug policy: A case example of two epidemiological monitoring systems. International Journal of Drug Policy 24(1): 30-37.

Roumeliotis, Filip. 2016. Ideological closure: drug prevention in a post-political society (Doctoral dissertation, Department of Sociology, Stockholm University).

Sacks, Harvey. 1995. Lectures on Conversation. (New edition; G. Jefferson and E.A. Schegloff, eds.). Oxford: Wiley. 
Sandler, Jen, and Renita Thedvall. 2017. Meeting ethnography: Meetings as key technologies of contemporary governance, development, and resistance. New York: Routledge.

Schudson, Michael. 2006. The trouble with experts - and why democracies need them. Theory and Society 35(5): 491-506.

Schwartzman, Helen B. 1987. The significance of meetings in an American mental health center. American Ethnologist 14(2): 271-294.

Schwartzman, Helen B. 2017. Conclusion: The Meeting and the Mirror. In Meeting ethnography: Meetings as key technologies of contemporary governance, development, and resistance, eds. Jen Sandler and Renita Thedvall, 158-178. New York: Routledge.

Scott, Marvin B., and Stanford M. Lyman. 1968. Accounts. American Sociological Review 33(1): 46-62.

Shapin, Steven. 1984. Pump and Circumstance: Robert Boyle's Literary Technology. Social Studies of Science 14(4): 481-520.

Shapin, Steven, and Simon Schaffer. 1989. Leviathan and the Air-Pump: Hobbes, Boyle, and the Experimental Life. Princeton University Press.

Silverman, David. 1998. Harvey Sacks: Social science and conversation analysis. New York: Oxford University Press.

Simmel, Georg. 1949. The Sociology of Sociability. American Journal of Sociology 55(3): 254-261.

Stevens, Alex. 2007. Survival of the Ideas that Fit: An Evolutionary Analogy for the Use of Evidence in Policy. Social Policy and Society 6(1): 25-35.

Stevens, Alex. 2010. Drugs, Crime and Public Health: The Political Economy of Drug Policy. London: Routledge.

Stevens, Alex. 2011. Telling Policy Stories: An Ethnographic Study of the Use of Evidence in PolicyMaking in the UK. Journal of Social Policy 40(2): 237-255.

Strauss, Anselm L., and Juliet Corbin. 1990. Basics of qualitative research: grounded theory procedures and techniques. Newbury Park, Calif.: Sage.

Swedberg, Richard. 2017. On the heuristic role of concepts in theorizing. In Theory in Action, eds. Håkon Leiulfsrud and Peter Sohlberg, 23-38. Leiden, The Netherlands: Brill.

Tieberghien, Julie, and Tom Decorte. 2013. Understanding the science-policy nexus in Belgium: An analysis of the drug policy debate (1996-2003). Drugs: Education, Prevention and Policy 20(3): 241-248.

Weiss, Carol H. 1979. The Many Meanings of Research Utilization. Public Administration Review 39(5): 426-431.

Weiss, Carol H. 1980. Knowledge Creep and Decision Accretion. Knowledge 1(3): 381-404.

Winter, Katarina. 2019a. Experiences and expertise of codependency: Repetition, claim-coupling, and enthusiasm. Public Understanding of Science 28(2): 146-160.

Winter, Katarina. 2019b. Everybody knows? Conversational coproduction in communication of addiction expertise. Diss. Department of Sociology, Stockholm University.

Publisher's Note Springer Nature remains neutral with regard to jurisdictional claims in published maps and institutional affiliations. 